\title{
EU, O PROTAGONISTA E A CENA: HABILIDADES \\ SOCIAIS, EMPARELHAMENTO NEURAL E EMPATIA
}

\section{Me, the protagonist and the scene: social skills, neural coupling and empathy}

\author{
Gabriel José Corrêa Mograbi*
}

\begin{abstract}
RESUMO
Análise filosófica e técnica pormenorizada (mas direcionada a não especialistas) de um artigo-alvo em neurociência com importância para o debate da relação entre emparelhamento neural, empatia e a capacidade projetiva em protagonistas de cenários ficcionais.
\end{abstract}

Palavras-chave: literatura naturalizada, empatia, emparelhamento neural, protagonistas, neurofilosofia.

\begin{abstract}
A detailed philosophical and technical analysis of a target-article in neuroscience, dedicated to non-specialists, focusing on an important debate concerning the relationship between neural coupling, empathy and projective capacity in main characters of fictional scenarios.
\end{abstract}

Keywords: naturalized literature, empathy, neural coupling, protagonists, neurophilosophy.

* Universidade Federal do Mato Grosso. 
1. InTROdução - ou, COMO ESTA PARTE SE ENCAIXA No RESTO (E SE SEPARA) DAS PARTES ANTERIORES

Gostaria de continuar de onde parei... Este texto pode ser entendido como uma sequência natural de meus dois artigos anteriores sobre as relações entre naturalismo e literatura publicados em Eutomia (UFPE), que são parte de um projeto de investigação capitaneado por Pedro Dolabela Chagas com minha ajuda, que já contou com dois dossiês temáticos em Eutomia, um evento científico na UFPR e agora com esta nova edição especial em Letras (UFPR) das relações entre Literatura e Naturalismo (este último termo entendido enquanto determinando uma abordagem marcada por um conjunto de aspectos coevolutivos, neurais, cognitivos e mentais). Quiçá, seja esse o diferencial da abordagem de nosso grupo em relação ao debate tal como conduzido nos Estados Unidos. Lá, viceja o "Darwinismo Literário" mas, ainda, não se integraram a este outros campos de estudos naturalistas igualmente vicejantes. Aqui, ainda que o debate esteja engatinhando e tenha sido "importado" por este grupo, já partimos de uma perspectiva mais integradora e da premissa de que um grau de consiliência maior é necessário para, minimamente, chegar-se a algum tipo de abordagem naturalista viável para a Literatura.

Mas, se como dito anteriormente, este texto poderia ser visto como uma sequência daqueles anteriores, os três artigos, entretanto, podem ser lidos como textos isolados e independentes. Não se perde a força nem a especificidade de cada peça de escrita lendo-se em separado. Nem uma ordem forçosa é primordial para uma compreensão de cada qual dos artigos. No entanto, lucra o leitor em vê-los como um plano sequencial. Há um ganho possível de um elemento bem-vindo ainda que não mandatório em, talvez, descortinar o processo que leva o redator de tais textos a seguir uma determinada senda de pensamento. o primeiro artigo, publicado em Eutomia (14 (1), p. 419-445, Dez. 2014) trata, primeiramente, do "ardido fragor de peleja encarniçada" entre "humanistas" e "naturalistas" no que concerne a uma disputa pela abordagem mais viável para a literatura e, também, da possibilidade de irmos além do paroquialismo departamental e da lógica de guilda medieval e estabelecermos um campo de estudos consilientes. Se, por um lado, aquele artigo defenestra alguns medos humanistas em relação ao atuais estudos naturalistas (evolutivos e cognitivos) como fobias (medos exagerados e irracionais), também, por outro, mostra as limitações da psicologia evolutiva como pretenso campo prioritário e proprietário na interpretação do comportamento humano e atenta, outrossim, para as limitações correntes dos estudos evolutivos no que concerne a uma demarcação precisa dos mecanismos da gênese da linguagem, mostrando quais devem 
ser algumas das verdadeiras preocupações com qual seja o hype em torno do atual "Darwinismo Literário" e quais são algumas das lacunas abissais que devem ser sanadas no intuito de promover uma abordagem mais consiliente.

Sempre, causou-me espécie que os assim chamados "Darwinistas Literários" tivessem pouca ou quase nenhuma entrada e interconexão com os pesquisadores que tratam da literatura por vieses neurocientíficos, cognitivos e mesmo pela via da psicologia experimental. Assim, considerando o problema da ainda enorme falta de consiliência nos estudos naturalistas da literatura, da falta de consiliência entre aqueles que justamente apregoam a consiliência como a saída e método, resolvi tratar em meu segundo artigo de alguns estudos em psicologia experimental social que mostram a relação entre sensibilidades e capacidades sociais e a exposição a gêneros de ficção, especialmente o romance. Aquele segundo artigo de minha autoria, em Eutomia (15 (1), p. 123-144, Jul. 2015), é fundamentalmente uma análise e revisão de dois artigos-alvo no campo da psicologia experimental que enfocam a relação entre sensibilidades interpessoais e a exposição a narrativas ficcionais. $\mathrm{O}$ primeiro experimento analisado por mim em meu segundo artigo tratará da relação mais geral entre narrativa e habilidades e sensibilidades cognitivo-sociais, mostrando que leitores de narrativas ficcionais têm melhores desempenhos em testes que medem sensibilidade e interpretação social em comparação a leitores de não-ficção. O segundo experimento por mim analisado, em meu artigo publicado em Eutomia, faz uma minuciosa discriminação entre gêneros literários na sua relação com sensibilidade social. Fica patente que exposição ao Romance é mais especificamente correlacionada com capacidade e sensibilidade social aumentada, apontando como o gênero de mais forte correlação com a posse de capacidades interpretativas (e mesmo de ação) em situações sociais. Uma das hipóteses mais relevantes analisadas no artigo é a de que o contato com narrativas poderia favorecer e desenvolver a cognição social à medida que familiariza o leitor com situações ficcionais nas quais uma inteligência social é requerida e o conhecimento de situações complexas entre personagem ficcionais é passível de transposição para situações reais presentes no cotidiano social. Uma versão mitigada de tal tese afirmaria que a narrativa pelo menos "afiaria" capacidades sociais, funcionando como um aperfeiçoamento de tais capacidades exercidas no mundo real. E, claro, uma terceira hipótese ainda poderia ser evocada na interpretação de qual seja a relação entre cognição social e exposição à ficção, ainda que seja a que menos atrai tais autores, ainda que logicamente viável, de que pessoas que já dispõem de fortes habilidades sociais e grandes capacidades empáticas são justamente aquelas que mais se comprazem em ler narrativas. Naturalmente, as hipóteses não são autoexcludentes. Além disso, independente de qual 
seja a relação causal básica, nota-se que pessoas frequentemente expostas a romances são, em geral, melhores intérpretes e agentes sociais em testes psicológicos que medem tais capacidades, quando comparadas a leitores de quaisquer outros gêneros.

Desta feita, ter-se-á em tela o artigo "Imagine All the People: How the Brain Creates and Uses Personality Models to Predict Behavior" (HASSABIS et al., 2014). Se no último artigo em Eutomia estudos criativos em psicologia experimental foram trazidos à baila para podermos pensar a relação das habilidades e sensibilidades sociais com a exposição à literatura e ao romance, neste artigo, traz-se uma nova área de conhecimento científico como apoio no estudo de tais mecanismos, a saber, a neurociência. No entanto, a advertência feita no último artigo publicado em Eutomia sobre a pouca inovação de meu texto é válida também para o presente artigo e seria uma perda de tempo não usar o mesmo texto, já que dificilmente eu descreveria de maneira mais lapidar o baixo pendor criativo e, ao mesmo tempo, a importância de divulgação, didatismo e poder explicativo de tal ensejo direcionado para um público de áreas de humanas e, especialmente, literatura:

Mais metalinguagem: reconheço que o artigo aqui ofertado não tem qualquer caráter revolucionário ou inovador. É apenas um redescrição crítica dos próprios artigos ou, quase, uma tradução resumida porém comentada. Inovadores ou revolucionários, talvez, sejam os estudos aqui focalizados. É importante notar que a exposição aqui iniciada não buscará estar pautada em tecnicismos ou jargões científicos, nem nos modos cientificamente preconizados para revisões de literatura (reviews) em revistas de ciência, muito mais sistemáticos, entretanto muito pouco descritivos e explicativos e sempre contando com um número muito maior de citações, mas com muito menos atenção dedicada a cada um dos experimentos citados. Este artigo é apenas uma tentativa singela de tornar acessíveis e palatáveis, ao público de língua portuguesa não especializado em psicologia experimental, alguns resultados destas últimas áreas que focalizam estudos promissores tendo como objeto a literatura. Entendo que o público para o qual escrevo é leigo em ciência, mas, de alguma maneira, interessado em conhecer estudos cognitivos em literatura. Sejam literatos, filósofos ou outros pesquisadores de formação humanista, todos dentre estes que possam estar interessados nas capacidades cognitivas envolvidas na leitura de literatura, na psicologia de capacidades sociais e sua relação com empatia e projeção em narrativas, teoria da mente e sua relação com os temas já aqui citados podem, de alguma forma, tirar certo proveito desse escrito. A natureza do trabalho aqui apresentado é "angélica" no sentido mais original do termo: hermenêutica de divulgação em favor da consiliência. Poupo a vocês, meus leitores, o trabalho de ler originais de áreas que 
Onde se lia psicologia experimental na citação acima, leia-se agora neurociência; onde se lia literatura, leia-se protagonista e narrativa (de maneira mais geral) e bola para frente! Considerando o limite de páginas que devo respeitar para estar em acordo com as normas da revista, terei de me ater a apenas um artigo-alvo e fazer referências esparsas a outros com temáticas congêneres, visto que analisaremos detalhada e didaticamente várias questões do experimento em tela, com vistas a uma explicação pormenorizada para leigos em neurociências que sejam interessados nas questões de narrativa, projeção e imaginação, empatia e sua importância social e também todo o pendor filosófico que tais considerações podem tomar se reunidas e analisadas de maneira suficientemente elucidativa. Ainda outra consideração metodológica deve ser feita: estarei me referindo constantemente ao artigo-alvo sem, no entanto, usar-me da prática corrente e preconizada da citação indireta pela obviedade de que este é nossa referência central e, praticamente, única. Expressões como "segundo os autores" e congêneres serão usadas para me referir mais diretamente aos relatos dos autores no artigo-alvo. Outro fator que deve ser ressaltado é que diferente dos outros artigos anteriores, nosso objeto de análise não é diretamente extrapolável para compreensão das capacidades envolvidas em narrativas literárias puramente ficcionais. $\mathrm{O}$ artigo aqui em questão faz considerações sobre tais limitações extrapolativas e entende que é esse contraste é importante por duas vias: a) algumas semelhanças entre as capacidades aqui exploradas e as capacidades propriamente necessárias para a compreensão literária podem ser interessantes em uma aproximação parcial da interconexão entre ambos os processos; b) a observação das salientes diferenças entre os dois processos permitem estabelecer aquilo que falta ser estudado cientificamente na abordagem de tais capacidades por tal experimento como tarefas a serem possivelmente estudadas em um futuro por projetos que visem estabelecer pontes mais estreitas entre as duas áreas (literatura e neurociência). De qualquer maneira, entende-se aqui que a análise de tal artigo pode ser de interesse para aqueles que tenham interesse no relacionamento das áreas e que minha intenção como autor do presente artigo é tão somente de me debruçar sobre uma das poucas referências científicas disponíveis em neurociência experimental que abordam a projeção imaginativa em personagens.

\section{A População do EXPERIMENTO}

Diferentemente dos estudos abordados em meu último artigo para Eutomia, o número de participantes no experimento aqui em tela é extre- 
mamente reduzido. Trata-se de um grupo de apenas 19 participantes (todos destros, sendo 10 mulheres) com idade média de 21.4 anos e diferença máxima de 3.2 anos. Para aqueles que não são familiarizados com as diferenças entre psicologia experimental e neurociência, é importante explicar porque um estudo de natureza semelhante em psicologia experimental conta com mais de 200 ou 300 participantes e um estudo neurocientífico conta com 19 ou $20 \mathrm{ou}$, se muito, 30 pessoas. O primeiro fator é obviamente econômico: um estudo fundado em questionários ou tarefas mais simples em termos de custo não onera o orçamento de um time de pesquisa mesmo com número populacional gigantesco, enquanto, especialmente no caso da ressonância magnética, usada no experimento em análise, tal custo é elevado. Outro fator é muitas vezes a própria pouca disponibilidade do equipamento, mesmo que pago a preço de ouro. Outra ainda é a necessidade de treinamento e preparação do participante (o que, além de dinheiro, custa muito esforço e tempo; e tempo, pelo menos no scanner, é dinheiro). Além disso, a preparação para a participação de uma tarefa em ressonância magnética pressupõe certo treinamento para uma habituação mínima a uma condição bem pouco comum para a maioria: a de estar numa máquina barulhenta, uma espécie de tubo ou túnel no qual o participante deitado numa maca é deslizado para dentro do scanner e tem de se manter ali quase imóvel, senão como um cadáver em um gavetão de necrotério, o mais próximo possível disso, durante a tarefa. Para muitos, a sensação de aprisionamento é angustiante ao ponto de impossibilitar a participação em um estudo; outros porém quase não sofrem com tal condição. Mas aí vem à tona outro fator que dificulta $o$ trabalho com amostragens gigantescas em experimentos de neurociência: a quantidade exorbitante de correlações, covariações e usos de múltiplas ferramentas estatísticas. Se com populações criticamente pequenas o volume de informação que precisa ser processado já constitui uma tarefa hercúlea no mais preciso sentido do termo, caso populações muito maiores fossem usadas a quantidade de informação a ser processada seria monstruosa. Entretanto, como disse o filósofo, lógico e matemático Frege (1897), "a conveniência do tipógrafo não é certamente o summum bonum" (da lógica), também não seria, parafraseando Frege, a conveniência do neurocientista na análise de dados o summum bonum da neurociência.

Assim, ainda que seja prática corriqueira que se trabalhe com amostragens pequenas na neurociência, devemos preferir que estas sejam tão maiores quanto o possível. Para aqueles que possam estar interessados neste problema de validade e poder estatístico, um artigo bastante crítico é sugerido é de Button et al. (2013), que sugere não só que estudos com baixo poder estatístico teriam uma chance diminuta de detectar um efeito verdadeiro mas, mesmo, que alguns estudos que parecem ter resultados 
significantes, estatisticamente falando, poderiam não refletir um efeito verdadeiro, por superestimar o tamanho do efeito e por seus resultados serem pouco passíveis de replicação por outros times de pesquisa. Por um lado, estudos com baixo poder estatístico poderiam gerar mais falsos negativos. Por outro lado, ele tem maior probabilidade de elicitar um efeito que seja tratado como uma descoberta, sendo, na verdade, apenas um falso positivo. 0 artigo, entretanto, recebeu réplicas bastante críticas sugerindo ser a tese dos autores por demais alarmista ou mesmo que ela estaria alvejando o adversário errado (QUINLAN 2013; BACCHETI, 2013, ambas cartas de resposta ao editor da revista em tela).

Inegavelmente, para encurtar a discussão sobre estatística em neurociência, eu diria que amostragens de maior tamanho são em geral mais sólidas estatisticamente e seriam muito bem vindas, principalmente quando o objeto de estudo é um efeito, em si mesmo, diminuto. Mas sugerir que os resultados em neurociência - ou pior, nas ciências biológicas em geral-, sejam todos (ou em grande parte) falsos positivos é um tanto hiperbólico, ainda que a crítica dos autores sejam uma importante arma política de admoestação da comunidade científica para a busca de padrões mais rigorosos e um alerta para aqueles que "compram por valor de face" e, acriticamente, resultados científicos. Um dos argumentos, entretanto, que podem vindicar a validade de descobertas em neurociência é a miríade de correlações e covariações que são produzidas em muitos estudos, com razoável coerência interna e grande viabilidade de afiguração de fenômenos que tenham contraparte de re e não sejam meras ilusões estatísticas. Entretanto, mostrar o calcanhar de Aquiles daquilo que se defende é medida de importância epistemológica e ética pautada por uma fidalguia acadêmica.

3. "Imagine All The People" - Estrutura do experimento: sobre TREINAMENTO DE CONHECIMENTO DOS PERSONAGENS REALIZADO ANTES DO ESCANEAMENTO

Antes do escaneamento cerebral propriamente dito, os participantes travaram contato com as personalidades dos quatro protagonistas ficcionais criados pelos experimentadores a partir daquilo que os autores chamam "uma estratégia combinada de treinamento e teste para compreensão e memória de tais aspectos de personalidade", baseada em evidências bem sucedidas e replicáveis de experimentos anteriores (LANDAUER; BJORK, 1978; ROEDIGER; KARPICKE, 2006).

As características das personalidades de tais personagens ficcionais foram transmitidas aos participantes por via de leitura, o que é uma 
medida especialmente interessante para os interesses de nosso dossiê. Por um lado, o fato da informação ser dada via leitura aproxima os resultados desse experimento do nosso tema mais geral, que é uma abordagem naturalizada da literatura, já que essa via é grata ao estudo da narrativa escrita. Por outro lado, não se poderia considerar que tal informação é dada por uma via narrativa propriamente dita, já que tais dados são transmitidos por descrições curtas e bastante objetivas e não em uma narrativa com algum grau de complexidade interna ou enredo. Segundo os autores, os participantes foram informados de que os experimentadores sabiam bastante sobre cada um dos 4 indivíduos a partir de entrevistas com eles, com suas famílias e amigos. Note-se que, apesar dos personagens serem ficcionais, a equipe de experimentadores apresenta aos participantes os personagens como se fossem pessoas de fato. Essa medida é, possivelmente, pensada para criar um maior grau de seriedade pelo lado dos participantes, na adesão a ideia de que tais indivíduos são de fato pessoas com personalidades definidas e perceptíveis pela interação com outras pessoas que foram capazes de afirmar e confirmar seus traços da personalidade. Diante de oportunas e sagazes indagações de um dos revisores do artigo, teço algumas considerações dos impactos da escolha dessa informação ou orientação (cueing) dos experimentadores: certamente, que tal medida já nos distancia um tanto de uma abordagem direta do fenômeno ficcional literário propriamente dito. $\mathrm{O}$ tipo de relação psicológica que o leitor teria com biografias ou relatos histórico-literários poderia ter afinidades maiores com tal procedimento aplicado pelos experimentadores do que a relação psicológica propriamente dita com obras puramente ficcionais. Ninguém em sã consciência acredita que Miss Dollar ou Leopold Bloom sejam, respectivamente, uma cadela e um homem de carne e osso. No entanto, seria exagerar por demais na importância de tal medida informativa acreditar que esta de fato gerasse nos participantes do experimento uma crença forte na factualidade da existência de tais personagens. Ela deve ser vista mais como uma medida de aumentar a credibilidade dos participantes no conhecimento prévio dos experimentadores sobre as personalidades dos protagonistas e o próprio engajamento na tarefa. Uma tarefa laboratorial já tem o pendor da artificialidade e ficcionalidade por si mesma e a medida tem o objetivo de mitigar esse descolamento do real que o laboratório pode gerar por seu próprio aspecto de "terra de ninguém". Por um outro viés ainda, poderíamos mais precisamente reinterpretar o escopo da importância de tal experimento para nossos fins: diferente do estudo analisado em meu último artigo em Eutomia, descrito mais acima, não estaríamos estudando tão diretamente relações entre competências literárias e sociais. Estaríamos almejando uma capacidade mais genérica: a relação entre a capacidade de projeção em personalidades de protagonistas a partir 
da própria personalidade do intérprete. Entendo que se tal capacidade aqui estudada é de interesse para a literatura não o é como sinonímia para tal processo especificamente mas, sim, indiretamente.

Também foi afirmado aos participantes, segundo o relato dos autores, que um pequena quantidade de informação sobre cada um dos indivíduos seria inicialmente oferecida e que os experimentadores estariam interessados em descobrir o quão capazes os participantes se revelariam de predizer o comportamento dos indivíduos a partir da informação que lhes era disponibilizada, o que é uma medida motivacional da população envolvida e já clarifica a intenção dos experimentadores sobre que tipo de performance é esperada dos participantes, funcionando, já, como orientação para a ação durante o experimento.

Uma medida para ampliar a proximidade de personalidade e assim sua predizibilidade - ou, quiçá mesmo, o "potencial empático" - é o fato de os personagens fictícios terem sido escolhidos segundo um critério de identificação com o gênero dos participantes. Sendo assim, 4 personalidades de mulheres para as participantes femininas e 4 personalidades de homens para os participantes masculinos. Outra medida que demonstra inteligência e precisão do desenho experimental em tal tarefa é que os nomes dos protagonistas foram hauridos entre os 10 nomes mais populares dados a bebês nascidos em 1990 no estado de Massachusetts, segundo dados do site de seguridade social dos Estados Unidos, o que naturalmente cria certa medida de familiaridade e viabilidade dos nomes enquanto parte da ambiência cotidiana dos participantes, já que a população foi arregimentada neste mesmo estado americano e nesta faixa etária (o experimento foi conduzido no Harvard Center for Brain Science). Os nomes dos personagens escolhidos foram: Mike, Chris, Dave e Nick e Ashley, Sarah, Nicole e Jenny. Outra medida que mostra um desenho experimental bem feito e preocupado em equalizar o grau empático entre os diversos participantes e os quatro personagens ficcionais que se lhes pedia predizer o comportamento é de que nenhum dos personagens ficcionais tinha homonimia com quaisquer dos participantes do experimento. Tal medida pode também ser vista como distanciando o experimento de uma relação mais direta com a ficção, especialmente, com certos gêneros onde nomes de personagens são muitas vezes raros ou mesmo inauditos e podem vir a ter cargas semânticas deliberadamente escolhidas e com relevância para a diegese ou para a caracterização da psicologia do personagem.

Cada um dos nomes de personagens ficcionais foi caracterizado por 12 afirmações sobre personalidade, 6 relacionadas à amabilidade, afabilidade ou agradabilidade (agreeableness) e 6 relacionados à extroversão a partir dos itens do Big Five Aspect Scales (DeYOUNG, 2010) e do Revised 
Neuroticism-Extraversion-Openness Personality Inventory (COSTA; McCRAE 1992). Segundo os autores, as afirmações sobre amabilidade continham sentenças formuladas positivamente (e.g., "Gosta de cooperar dom os outros") e negativamente (e.g. "Pode ser frio e indiferente").

Ainda seguindo a análise dos próprios autores, afirmações sobre o grau de extroversão dos personagens ficcionais também foram apresentadas de maneiras tanto positivas (e.g., "É extrovertido, sociável”) quanto negativas (e.g. "É, às vezes, tímido, inibido"). Vale lembrar ao leitor com pouca familiaridade com o assunto aqui em tela que tais escalas já são amplamente testadas, replicadas e revistas tanto em experimentos de psicologia experimental social como em neurociência afetiva e são usadas como medidas já sólidas e amplamente validadas.

Também é reportado pelos autores que, enquanto os participantes liam as 12 afirmações sobre cada um dos personagens ficcionais, recebiam uma fotografia e o nome do personagem. Assim, os participantes do experimento vêm fotografias e recebem informações precisas (categoricamente adjetivadas) sobre cada personagem: isto parece configurar uma imagem muito mais rígida de cada figura do que aquela que se costuma ter dos personagens ficcionais, cuja caracterização (física, moral, psicológica...) tende a ser bem mais vaga ou fuzzy do que em uma narrativa puramente ficcional. Mais uma vez, esta decisão dos pesquisadores diminui a dimensão da extrapolação dos resultados da pesquisa para a análise da relação de leitores com personagens puramente ficcionais. A liberdade projetiva é diminuída em relação ao que ocorre em uma narrativa puramente ficcional, especialmente em relação às formas modernas de romance, um tanto mais fragmentárias e não-lineares. Mas, voltando-se ao experimento, com esse conjunto de material informativo, os participantes avaliavam 18 itens (respondendo disjunções simples de afirmação de verdadeiro ou falso) sobre cada um dos protagonistas, cada qual ao seu tempo: 72 itens no total, e.g. "Gosta da ideia de ser lhe feita uma festa surpresa, verdadeiro ou falso". Após esta etapa, os participantes tiveram a oportunidade de estudar as 12 afirmações sobre cada um dos protagonistas, antes de um teste livre de recordação sobre características dos personagens no qual, naturalmente, o acesso a tais afirmações não era facultado e, desta feita, cada um dos participantes era instruído a "descrever seus pensamentos gerais e impressões sobre este indivíduo em 3 a 4 sentenças”. Note-se que este tipo de teste dá ao participante a liberdade de sumarizar, nestas três ou quatro sentenças, a informação obtida na leitura das 12 afirmações recebidas sobre os participantes, depois que já existe algum grau de conjectura sobre como tais protagonistas agiriam nos contextos de ação propostos. Tal procedimento vai aparelhando o sujeito experimental de recursos para ir criando o que os autores chamam de um 
"modelo de personalidade". Ainda, segundo o relato dos autores, a ordem de apresentação e de personalidade, nome e emparelhamento de fotografias foi randomizada entre os participantes, o que é uma medida padrão para evitar tendências ou previsões antecipadas.

\section{TREinamento de imaginação DE CEnAS}

Os autores relatam que pedem, então, aos participantes que imaginem vividamente 12 locações cotidianas, tais como bar, restaurante ou banco, e para que descrevam tais cenários com o máximo de detalhes. Vale lembrar que tal estratégia que já tinha sido usada e validada por experimentos anteriores, que contavam com parte da equipe presente (HASSABIS, KUMARAN; MAGUIRE, 2007; HASSABIS, KUMARAN, VANN; MAGUIRE, 2007). Foi explicitamente dito aos participantes para não evocar uma memória de um lugar real (ou mesmo parte de uma locação real), mas para, em vez disso, construírem em sua imaginação um lugar completamente novo, sem base em memórias ou parte de memórias de lugares de fato, que tivessem experienciado. Esta medida de apelar para um cenário "puramente" ficcional, sem base "nenhuma" ${ }^{1} \mathrm{em}$ memória de lugares de fato, traz já uma aproximação interessante no que concerne à criação de um cenário imaginário, sem necessária conexão com a realidade, tão presente na leitura de narrativas. Se fizemos considerações sobre as limitações que outras medidas de orientação anteriormente descritas poderiam gerar na extrapolação dos resultados de tal experimento para a compreensão do fenômeno literário da projeção em personagens e cenários, muito possivelmente, a medida logo acima descrita potencializa esta ponte.

Também foi informado aos participantes no estudo que instruções para reimaginar estas mesmas locações apareceriam múltiplas vezes durante a sessão de escaneamento e que, em cada resposta, eles deveriam manter a imaginação neste mesmo lugar, tão exatamente a mesma quanto o possível. De novo, entende-se que tal habilidade cognitiva de imaginação é fundamental para que um leitor acompanhe uma narrativa. Manter na memória e, a cada vez, retomar a capacidade de imaginar as locações de um romance, por exemplo, é necessário para seguir tal narrativa, ainda que não tenhamos qualquer memória autobiográfica direta dessas locações. Segundo os autores, tal tipo de tarefa de imaginação exemplifica uma

1 As aspas nos termos "puramente" e "nenhuma" são colocadas aqui para alertar que por mais que tal comando seja dado, entende-se que toda construção de cenário ficcional por mais que se almeje nova tem algo da experiência anterior, mesmo na mais pura ficção. 
"simulação mental" (HASSABIS; KUMARAN; MAGUIRE, 2007; HASSABIS; KUMARAN; VANN; MAGUIRE, 2007). Segundo os autores, diferentemente da recordação autobiográfica, eventos imaginados podem ser manipulados e sistematizados e todos os participantes poderiam imaginar, cada qual, os mesmos cenários, e poderiam fazê-lo de tal maneira, múltiplas vezes. Assim, o conteúdo pode ser controlado e mantido com bom grau de confiabilidade (HASSABIS; KUMARAN; MAGUIRE, 2007; HASSABIS; KUMARAN; VANN; MAGUIRE, 2007; ADDIS et al., 2009). Na sequência da explicação desta parte do processo do experimento, os autores afirmam que, imediatamente antes do escaneamento, foram apresentados aos participantes fotografias para cada um dos protagonistas. Os pesquisadores requisitaram que eles atestassem o nome da pessoa em questão e três palavras descrevendo a personalidade de cada um desses protagonistas. Durante o escaneamento propriamente dito, o mesmo processo foi usado para garantir a estabilidade da representação das personalidades dos protagonistas por toda a duração do processo: foram mostradas fotos dos protagonistas aos participantes e de novo foi perguntado o nome da pessoa com a requisição de 3 palavras que descrevessem as suas personalidades nos intervalos da tarefa. Os participantes também relataram o conteúdo de dois dos eventos imaginados para duas cenas randomicamente selecionadas para cada um dos 4 protagonistas como também para a condição "self". Este procedimento é uma estratégia de checagem do cumprimento e adesão à tarefa. Isso garante não só que o participante é capaz de manter na memória os personagens mas, também, os cenários em questão. No entanto, há mais uma diferença aí em relação à ficção de longa extensão, em que os lugares mais importantes para o enredo nunca são descritos uma única vez, tendo, pelo contrário, a sua descrição distribuída ao longo da narrativa em vários segmentos descritivos distintos - que vão, a cada vez, atualizando a memória do leitor em relação à imagem específica do lugar. O leitor não encontra a descrição uma única vez apenas, devendo mantê-la viva na memória durante toda a duração da leitura: pelo contrário, ele encontra elementos pontuais que retomam aquela descrição inicial, atualizando a sua memória sempre que o autor intui necessário. Outro ponto de relevo é que em narrativas minimamente complexas o leitor tem de atualizar essa compreensão das locações com dados novos, elementos narrativos que vão redirecionando e redimensionando a malha semântica da diegese. Assim, a capacidade de manter na memória dados sobre o cenário é fator importante para a compreensão da situação literária e é aqui estudada, entretanto, essa capacidade de reconstrução dos cenários segundo novos dados não é endereçada em tal experimento, muito menos com a complexidade que um romance moderno poderia apresentar devido a seu caráter fragmentário e não-linear. 


\section{Sobre A TAREFA REALIZAdA NA RESSONÂNCIA MAGNÉTICA}

Segundo os autores, durante a sessão de escaneamento foram apresentadas aos participantes orientações (cues) em texto descrevendo um evento curto que se desenrolava em cada uma das locações pré-imaginadas, com a presença de um dos quatro protagonistas. Por exemplo: "na rua vê um veterano de guerra sem-teto pedindo esmola - Sarah." Os autores atestam que os participantes foram instruídos para imaginar mentalmente (play out) essas 12 vinhetas, cada qual durando um período de 10 segundos, concentrando-se nas ações, pensamentos e sentimentos dos protagonistas. Depois os participantes avaliaram o evento imaginado em termos de vivacidade (ou nitidez - vividness) e confiança em afigurar com precisão o protagonista naquela situação - em ambos os casos, numa escala de 1-5. Relataram os autores que cada tentativa (trial) durou 25 segundos consistindo de: um texto de orientação contendo informação em relação à locação, evento e protagonista (ou a orientação "Self" ou "Vazio" - 5 segundos); um período de simulação mental (10 segundos); avaliações sobre vivacidade e confiança ( 7.5 segundos); e um período de descanso (2.5 segundos). Note-se que a condição "self" e "vazio" são importantes para a posterior análise do experimento e isolamento de variáveis, já que permitem comparar as diferenças no processamento informacional cerebral relativas à imaginação dos 4 protagonistas nas cenas, de si mesmo na cena (como protagonista) e mesmo de uma cena vazia sem protagonista. Isto permite análises mais pormenorizadas de cada capacidade, de cada tema e das áreas cerebrais envolvidas em cada uma dessas tarefas individualizadas.

É interessante notar, também, que uma "condição basal" (baseline condition - condição de avaliação de estado inicial) foi usada para estabelecer uma medida de respostas dos sujeitos sobre a variável dependente antes da implementação da manipulação experimental. A razão principal para o uso de uma condição basal é que tal procedimento permite identificar um patamar de resposta dado por respostas e suas capacidades preexistentes antes da influência da manipulação em questão em um experimento. Condições basais são uma medida de segurança importante no que concerne à validade estatística de um experimento com amostragem pequena, para que se possa ter uma baliza de capacidades anteriores à manipulação experimental, como já explicado. No caso do experimento em tela, a condição basal foi uma contagem de sílabas. Segundo os autores, durante a contagem ocorreu: uma orientação em forma de texto (5 segundos); um período de contagem permitindo ao participante determinar o número de sílabas na informação verbal (10 segundos); uma questão referente ao caráter par ou ímpar do número de sílabas e uma avaliação da confiança com a qual fizeram seu 
julgamento ( 7.5 segundos); por fim um período de descanso (2.5 segundos).

Afirma-se também que a ordem das tentativas do experimento foi contrabalanceada entre participantes para não que duas tentativas adjacentes envolvendo a mesma locação ou a mesma condição não acontecessem (o que naturalmente é uma medida comum e muito bem-vinda para evitar a criação de tendências indesejadas relativas à repetição). Tentativas com pontuações com vivacidade e confiança acima de três (numa escala de 5 pontos) foram retidas para subsequente análise da ressonância magnética.

Duas condições adicionais envolvendo julgamento de características foram conduzidas, mas por não serem relevantes para os objetivos mais gerais do experimento não são assim relatadas no artigo.

\section{Resultados}

\subsection{DADOS COMPORTAMENTAIS}

Os autores afirmam que, no geral, as avaliações dos participantes de vivacidade e confiança foram altas, sendo a avaliação média superior a quatro (numa escala de máximo 5), indicando forte observância e adesão à tarefa. A avaliação de vivacidade feita pelos participantes quando imaginando os quatro protagonistas, a si mesmos (condição self) e a locação vazia revelou um efeito principal significante ( $F 5,14=3.87, \mathrm{P}<0.05)$. Segundo os autores, não foram observadas diferenças emparelhadas (pairwise differences) quando há correção para múltiplas comparações (correção de Bonferroni ${ }^{2} \alpha<0.05$ ). A tendência estatisticamente mais sólida e significativa se deu, (como plenamente esperável), na vivacidade ou nitidez entre a imaginação de si mesmo em uma determinada situação (condição self) e no caso da imaginação do comportamento dos dois protagonistas que foram inferiormente avaliados em termos de amabilidade (afabilidade, agradabilidade ou, no original, agreeableness). Projetamo-nos mais facilmente no que nos é semelhante. Houve, também, uma diferença estatisticamente significativa entre as avaliações de confiança entre como os participantes e os protagonistas agiriam (F4,15 $=5.16, \mathrm{P}<0.01)$. A confiança dos participantes em imaginar seu próprio comportamento foi, naturalmente, como era esperável, muito superior do que a confiança em imaginar os dois protagonistas com avaliação pior em termos de amabilidade (aplicada à correção de Bonferroni, $\alpha<0.05$ ). Entretanto,

2 A correção de Bonferroni é uma forma de compensar o problema da multiplicidade de hipóteses advindo da situação de que, quando um número grande de hipóteses é testado, a probabilidade de um evento raro aumenta e, da mesma maneira, a probabilidade de rejeição da hipótese nula que, ao seu turno, normalmente afirma que não existe relação entre dois fenômenos medidos. 
algo a ser ressaltado e de grande importância é que não foram observadas diferenças significativas entre os 4 protagonistas no geral. As diferenças são dadas não na avaliação geral dos 4 protagonistas entre si por todos os participantes mas, sim, com relação ao grau de amabilidade dos protagonistas na visão de cada um dos participantes e ao grau de afabilidade e afinidade específica de cada um dos participantes com cada um dos protagonistas. Tais resultados sugerem fortemente que as pessoas se projetam de maneira imaginativa mais facilmente naqueles protagonistas com os quais tem maior afinidade ou aos quais entendem ter certo grau mais positivo de afabilidade e que o mesmo processo, que talvez pudéssemos chamar de empático, não se dá com a mesma magnitude quando os sujeitos experimentais tentam prever ou se projetar num cenário de ação de personalidades ou protagonistas com os quais têm menor grau de afabilidade. Outro dado afirmado pelos autores é de que, na tarefa na qual os participantes tinham de determinar se o número de sílabas do material verbal apresentado era par ou ímpar, os participantes tiveram resultados superiores ao acaso.

\subsection{Dados de neuroimagem}

Segundo literatura específica sobre o tema (NAKAO; OHIRA; NORTHOFF, 2012; OIN; NORTHOFF; 2011; BUCKNER; CARROLL, 2007; HASSABIS; MAGUIRE, 2007; SCHACTER et al., 2007, 20083), a rede padrão (default mode network, ou ainda default network) é composta de várias regiões cerebrais com amplo comércio de informação e com atividade altamente correlacionada. Essas evidências sólidas mostram que a rede padrão é mais comumente ativa quando um indivíduo não está centrado em tarefas advindas das vias aferentes (externas) e sim quando o cérebro se encontra em situações como, por exemplo, divagação mental. Entretanto, a rede padrão mostra importante e aumentada atividade quando alguém está pensando em si mesmo, lembrando do passado, planejando o futuro e, de maneira especialmente interessante para nosso tema, pensando sobre os outros. Buckner e Carrol (2007, citados pelos autores do artigo-alvo) atestam que quando pensamos sobre o futuro - ou como nos é especialmente interessante para os fins de nosso artigo, quando nos projetamos em ações de outras pessoas -, nós o faríamos usando a rede padrão. Tanto no caso da prospecção de situações futuras como no caso da lembrança do passado e da concepção do ponto de vista alheio, usaríamos essa rede padrão que é fortemente relacionado ao 
"eu" de quem a usa, mostrando que imaginar uma ação alheia passa fundamentalmente por se projetar em tal situação, o que de novo confirma certa visão de empatia enquanto projeção do eu em "outros eus" que será discutida em outros pontos desse artigo. Os autores do nosso artigo-alvo partem da hipótese de que imaginar ou simular situações de comportamento alheio com base em suas personalidades envolveria essa rede, tese compartilhada por outros autores já citados desde o começo dessa seção de nosso artigo e com ampla malha de referências empíricas a seu favor.

Para confirmar o engajamento da rede padrão (default network) através das 3 condições, os autores compararam cada uma destas condições com a tarefa de contagem de sílabas, na qual os participantes estiveram apenas engajados em características superficiais da informação verbal apresentada. Através de 3 contrastes emparelhados, as tarefas de imaginar os protagonistas, imaginar a si mesmos na cena e imaginar uma cena vazia foram comparadas à tarefa de contagem como condição de base ou condição inicial (baseline condition). Todas as tarefas de imaginação foram associadas como um aumento significativo da atividade cerebral em regiões da rede padrão (default network), incluindo córtex prefrontral medial (mPFC), córtex cingulado posterior (pCC), lobo temporal médio (MTL), córtex temporal lateral (LTC), polo temporal, lobo parietal inferior (IPL) e os giros superior e inferior frontal. Segundo os autores, esse padrão de atividade é consistente com atividade observada quando da construção de uma cena (HASSABIS; KUMARAN; MAGUIRE, 2007; HASSABIS: KUMARAN; VANN; MAGUIRE, 2007) e também na imaginação de eventos futuros possíveis (SCHACTER et al., 2007).

Apenas para fazer uma consideração de muitas possíveis para aproximar o experimento do tema que nos interessa mais especialmente, que é a narrativa, poderíamos nos debruçar sobre a funcionalidade do lobo temporal médio. O lobo temporal médio é fundamental para a capacidade de memória de longo termo ou memória declarativa. A memória declarativa, também chamada de denotativa, divide-se em dois tipos: memória episódica e memória semântica. A memória episódica, como o próprio nome indica, refere-se a eventos específicos (como, por exemplo, o recuo de Toninho Cerezo interceptado por Paolo Rossi em Brasil vs. Itália na Copa de 1982 ou, para nos aproximarmos ao nosso tema, uma determinada ação de um personagem em um momento específico de uma narrativa, como Bentinho penteando Capitu no capítulo 33 de Dom Casmurro, "O Penteado"). A memória semântica, por sua vez, mostra certo acúmulo de conhecimento geral sobre o mundo e aponta para o caráter conceitual da relação de termos e ideias (como por exemplo a noção de recuo de bola, atacante, gol etc. ou de prolepse, narrativa e flashforward). A memória semântica é inclusive um 
dos elementos necessários para o aprendizado de novos conceitos ou ideias a partir de estruturas que já acumulamos (quando, por exemplo, alguém faz a ilação de que uma prolepse em uma narrativa escrita tem semelhanças estruturais com um flashforward em cinema, certamente, fez uso de sua memória semântica e assim da área cerebral aqui referida).

Em seguida, os autores distinguem contribuições do processamento de ordem social e espacial conduzindo 2 contastes: (1) imaginar o protagonista na cena comparado com imaginar uma cena vazia (sem pessoas); e (2) imaginar a si mesmo em comparação ao ato de imaginar uma cena vazia.

É afirmado pelos autores que, considerando-se a condição de imaginação de uma cena vazia, o contraste entre imaginar os protagonistas e a si mesmo (self) revelou regiões nas porções ventrais, dorsais e anteriores do córtex pré-frontal medial (mPFC), córtex cingulado posterior (pCC), lobos temporais e córtex occipital. Segundo os autores, essas regiões cerebrais são mais engajadas no processamento social durante a simulação de interação do que no caso da mera imaginação de uma cena vazia. O contraste entre imaginar a si mesmo na cena e imaginar os protagonistas revelou maior atividade no hipocampo, córtex pré-frontal medial (mPFC), e outras regiões.

Nenhuma região cerebral demonstrou uma resposta de atividade cerebral maior para a condição de imaginar um protagonista do que na condição de imaginação de si mesmo (self). Segundo os autores, duas questões foram então endereçadas: (a) Onde no cérebro a informação sobre a personalidade dos protagonistas é representada?; e (b) onde a informação sobre a identidade de cada um dos quatro protagonistas é representada?

Para responder a tais questões, os autores lançaram mão de MVPA $^{4}$ para determinar se tais regiões cerebrais continham informação o suficiente para justificar tais condições. Para examinar onde a informação sobre personalidade seria representada, uma classificação de duas vias foi realizada com tentativas envolvendo protagonistas que envolviam traços de personalidade em comum (e.g., amabalidade alta) que foi colapsada em uma condição única. Os autores encontraram conglomerados neuronais específicos (clusters) numa região dorsal do córtex prefrontal medial (mPFC) e no córtex temporal lateral esquerdo que permitiam diferenciar o processamento entre protagonistas com alta e baixa amabilidade.

Protagonistas com alta e baixa extroversão puderam ser discriminados com bases das diferenças de respostas do córtex cingulado posterior, por sua vez. Para conseguir localizar onde a informação sobre a identidade

4 Multi-voxel pattern analysis é uma técnica de análise e comparação de padrões de atividade distribuída. Tal abordagem multivariada permite que informação de vóxeis pertencentes a uma região sejam conjuntamente analisados. 
dos protagonistas seria representada, uma classificação de 4 vias foi realizada visando, obviamente, identificar cada qual dos 4 protagonistas. Conglomerados neuronais nas porções anterior e dorsal do córtex pré-frontal medial (mPFC) (com graus de ativação superiores a estas observadas para amabilidade) confiavelmente discriminaram os 4 protagonistas.

Modelos de personalidades diferentes são, dessa forma, associados a padrões de atividade cerebral detectáveis e únicos no córtex pré-frontal medial mPFC. Os autores foram capazes de inferir apenas baseados em padrões de ativação neural em qual dos 4 protagonistas cada um dos sujeitos experimentais estava pensando em cada ocasião de tentativa. Finalmente, os autores buscaram avaliar a hipótese de que a porção anterior do córtex pré-frontal medial reúne e atualiza modelos de traços de personalidade de outras pessoas processados pelo córtex temporal lateral, córtex pré-frontal medial dorsal e córtex cingulado posterior.

Para uma apreciação mais profunda de tal hipótese, uma análise de conectividade funcional foi operada visando demarcar se o córtex pré-frontal medial anterior se correlacionava com LTC, dorsal mPFC e pCC durante a simulação mental dos 4 protagonistas. Em tal análise, os autores avaliaram a conectividade funcional do MPFC anterior para as condições envolvendo os 4 protagonistas. Para todos os 4 protagonistas, a atividade do anterior $\mathrm{mPFC}$ anterior foi significantemente correlacionada com padrões distribuídos de respostas de vóxeis. A conectividade funcional com o MPFC anterior foi significante para o LTC (média BSR $=3.5, \mathrm{P}<0.001$ ), $\mathrm{mPFC}$ dorsal (média BSR $=4.1, \mathrm{P}<0.001$ ) e pCC (média BSR $=3.2, \mathrm{P}<0.002$ ). Durante simulações sociais imaginadas, as regiões cerebrais que codificam informação sobre personalidade de outrem (protagonistas) estavam, dessa maneira, funcionalmente emparelhadas com a região que codifica identidades individuais dessas pessoas. Além disso, a conectividade também se estendeu a outras áreas da rede padrão (default network), incluindo-se aí o IPL, córtex retrosplenial e hipocampo.

\subsection{Análise de Controle de GÊnero}

Considerando a importância das diferenças de gênero no comportamento social, os autores reanalisaram seus dados para avaliar o efeito do gênero em seus resultados. Na análise de grupo usando PLS (Partial Least Square Regression), a atividade cerebral para ambos os gêneros covariou junto e não foram encontradas interações por gênero nas tarefas que tivessem relevância estatística. Para o MVPA, os autores confirmaram os mesmos padrões de resultado, mesmo usando gênero como uma covariável sem interesse no segundo nível da análise. Dessa maneira, esse nível da 
análise não evidenciou que gênero chegou a ter uma relevância estatística quando usando como medida de controle para os resultados de capacidade de projeção no comportamento dos protagonistas.

Além disso, os autores avaliaram se havia alguma diferença estatisticamente sólida numa análise de cérebro inteiro da questão de gênero que pudesse discriminar entre níveis de amabilidade e extroversão e na relação com cada um dos 4 protagonistas. Nenhum padrão significativo foi observado. Entretanto, tais resultados não podem ser considerados como sequer sugerindo que exista uma indiferença da questão de gênero na cognição social. Os próprios autores reconhecem que a literatura especializada aponta para significantes diferenças de gênero na cognição social e admitem que a incapacidade de observação de diferenças de padrões poderia ser devida a falta de uma maior amostragem. Assim, poderia ser entendido que a incapacidade de observação da importância da variável "gênero" fosse mais devida ao baixo poder estatístico de uma amostragem que contou com apenas 19 pessoas (10 mulheres e 9 homens). Se mesmo com a amostragem pequena os todos outros fatores aqui avaliados foram, dentro desse quadro, muito bem fundamentados estatisticamente pelos padrões dos resultados, no caso do gênero, talvez uma população significantemente maior fosse necessárias para elicitar tais resultados. Vale lembrar, também, como já afirmado por mim no começo deste artigo e informado pelos próprios autores do experimento e do artigo, que os personagens fictícios foram escolhidos segundo um critério de identificação com o gênero dos participantes que é uma medida que balanceia a questão de gênero e pode contribuir para o efeito aqui descrito.

\section{Algumas considerações filosóficas À guiSA De CONCLUSÃo}

Além dos dados neurocientíficos confirmarem a maior vivacidade ou nitidez da imaginação das próprias ações em relação às de outrem, a partir também de testes comportamentais, os autores trazem à baila um reforço da ideia de que somos, naturalmente, mais eficazes na imaginação daquilo que nos é mais próximo. O fato já relatado de que a imaginação de cenas com os protagonistas que são classificados por autodeclaração como mais amáveis ou afáveis gera atividade cerebral maior em comparação àqueles com os quais os sujeitos experimentais tem menor afinidade, não só confirma a eficácia dos testes comportamentais como acaba por demonstrar a grande viabilidade da hipótese de que a projeção imaginativa trabalha em graus de proximidade, ideia que filosoficamente foi defendida por Hume em caráter visionário: 
they reflect each others emotions, but also because those rays of passions, sentiments and opinions may be often reverberated and decay away by insensible degrees" (HUME, 2000).

Independentemente da questão terminológica de qual seja o melhor nome conferível a tal capacidade, seja ela nomeada simpatia, empatia ou capacidade projetiva, o que nos interessa aqui é o fato de que, ao nos colocarmos na posição de representação do comportamento alheio, por mais que comecemos tal projeto de maneira mais intelectualizada e representativa (pelo menos no caso do experimento aqui em tela e no caso da literatura em geral), passamos a uma dimensão afetiva quando somos capazes de recriar as condições de representação de tais situações com a vivacidade necessária para que tal situação seja emocionalmente experimentada. Esse processo foi sumarizado em uma sentença lapidar de Hume (2000, p. 427): "The conversion of an idea into an impression by the force of imagination". Em outra passagem Hume esmiúça essa ideia da seguinte forma:

Tis indeed evident, that when we sympathize with the passions and sentiments of others, these movements appear at first in our mind as mere ideas, and are conceived to belong to another person, as we conceive any other matter of fact. Tis is also evident, that the ideas of the affections of others are converted into the very impressions they represent, and that the passions arise in conformity to the images we form of them (HUME, (2000, p. 319-20).

Naturalmente, descobertas como neurônios-espelhos e outras formas de projeção e emparelhamento neural mais tácitas e menos intelectuais demonstram que essa não é a única via possível para tal processo. Aliás, demonstram que essa capacidade é mais a exceção do que a regra no que concerne o fenômeno empático em geral. Assim, podemos dizer que a capacidade descrita por Hume, mesmo sendo o empirista mor de seu tempo, é por demais intelectualizada para ser o padrão geral pelo qual a projeção de um eu em outro se dá. No entanto, no caso da projeção em narrativas, em casos de projeção personagens ficcionais via leitura, parece que a descrição do filósofo tende a ser bastante próxima do processo neural em questão. Para além do dissenso contemporâneo de filósofos, psicólogos e neurocientistas que se digladiam pela defesa de apenas uma das visões de como esses processos se dão (uns mais centrados em visões mais básicas e perceptuais e outros mais centrados em uma Teoria da Mente (ToM), Gallagher e Hutto sumarizam que ambos os processos (mais automatizados e mais intelectualizados) podem ser importantes diante de diferentes contextos: 
derstanding of others may involve one or both of these paths - employing a narrative-informed folk psychology and/or a less mediated narrative practice - and which one is appropriate will depend on the context. (GALLAGHER and HUTTO, pp. 29, 30, 2008)

Gallagher (2012) em outro artigo de sua autoria (nesse caso sem companhia de Hutto) entende que a competência narrativa e comunicativa seja importante mesmo para situações cotidianas mais complexas e, assim, no caso da interpretação de narrativas propriamente ditas, em especial as mais fragmentárias e intelectualizadas poderíamos pelo menos supor que tal capacidade seja não só central como fundamentalmente necessária:

The use of mentalising inferences, however, seems to be more the exception than the rule, and would make empathic understanding more a matter of observational logic than of being moved by the other's situation. Rather than pursuing some form of TT or ST, or some hybrid version of ToM, I've tried to make the case for the importance of communicative and narrative competency to address this issue. The capacities of primary and secondary intersubjectivity, which characterize our human interactions in early and late infancy, are not replaced by a cold theoretical logic, or a self-controlled simulation. They are extended through language and autobiographical memory into a narrative competency that allows us to recognize the other person's circumstance and to construct an appropriately nuanced narrative understanding.

Gallagher argumenta que a competência narrativa seria um desenvolvimento de competências mais básicas advindas das capacidades para a intersubjetividade primária e secundária. Afirma também que "inferências mentalizantes" seriam muito mais a exceção do que a regra. Concorda-se que essa é tônica quando falamos da empatia em geral ou na experiência cotidiana de relações empáticas com o comportamento alheio que, na maioria das vezes, poderia se dar de maneiras bem menos intelectualizadas e muito mais automáticas. Entendo que Gallagher consegue criar um quadro de análise complexo e equilibrado para o trato da empatia como fenômeno global da experiência humana intersubjetiva. No entanto, vale a pergunta: se a "inferência mentalizante" não é tônica prioritária e mais fundamental da experiência empática em geral, se ela é mais exceção que regra, será que tal equação não se inverteria no caso da narrativa literária? Não seria justamente a literatura o espaço de cognição superior e intelectualizada onde a a exceção à regra acaba por virar regra? Onde fazemos emoções e imagens a partir das palavras, em vez de, a partir de emoções e imagens elaborar conceitos, parece que a inversão da equação é a melhor medida. A visão de Hume parece ser por demais intelectualizada para dar conta do 
fenômeno da empatia na variedade das emperiências cotidianas e práticas de contextos reais. Mas, justamente, o que faz este autor errar em suas análises do fenômeno global da empatia, parece que é o que o faz acertar se recondicionarmos suas análises ao diminuto escopo da empatia na leitura de textos ficcionais.

Entretanto, a validade de parte das ideias de Hume segue intocada: não só poderíamos enxergar similaridades entre as descobertas do artigo-alvo e do resto de nossas referências com as intuições de Hume no que concerne aos graus de sensibilidade projetivos ou empáticos fortemente relacionados com o grau de conformidade e afinidade com os personagens nos quais nos projetamos mas, também com a própria ideia de que por mais vívida e poderosa que seja tal capacidade projetiva sempre há uma menor intensidade na projeção em outrem do que na relação de projeção em situações possíveis ou futuras nas quais se afigura ou se imagina a si mesmo, mesmo que estivéssemos falando do prosaico caso no qual imaginamos o que acreditamos faríamos no lugar do personagem diante de um qualquer dilema ou necessidade de escolha importante. Assim, gostaria de fechar numa nota poética e irônica. Como diria Caetano: "narciso acha feio o que não é espelho".

\section{REFERÊNCIAS}

ADDIS, D. R.; PAN, L.; VU, M. A.; LAISER, N.; SCHACHTER, D. L. Constructive episodic simulation of the future and the past: distinct subsystems of a core brain network mediate imagining and remembering. Neuropsychologia, v. 47, p. 2222-2238, 2009.

BACCHETI, P. Small sample size is not the real problem. Nature Reviews Neuroscience, Correspondence, v. 14, 2013.

BUCKNER, R. L.; CARROLL. D. C. Self-projection and the brain. Trends in Cognitive Sciences, v. 11, p. $49-57,2007$.

BUTTON, K. S.; IOANNIDIS, J. P.; MOKRYSZ, C.; NOSEK, B A.; FLINT, J; ROBINSON, E. S. J.; MUNAFÒ, M. R. Power failure: why small sample size undermines the reliability of neuroscience. Nature Reviews Neuroscience, v. 14, p. 365-376, May 2013.

COSTA, P. T. J., McCRAE, R. R. NEO PI-R professional manual. Odessa (FL): Psychological Assessment Resources Inc., 1992.

DeYOUNG, C. G. Personality neuroscience and the biology of traits. Social and Personality Psychology Compass, v. 4, p. 1165-1180, 2010. 
FONG, K.; MULLIN, J. B.; MAR, R. A. What You Read Matters: The Role of Fiction Genre in Predicting Interpersonal Sensitivity. Psychology of Aesthetics, Creativity, and the Arts - American Psychological Association, v. 7, n. 4, p. 370-376, 2013.

FREGE, G. Über die Begriffsschrift des Herrn Peano und meine eigene. Berichte über die Verhandlungen der Königlich Sächsischen Gesellschaft der Wissenschaften zu Leipzig. Mathematische-Physische Klasse, v. 48, p. 361-78, 1897.

HASSABIS, D.; MAGUIRE E. A. Deconstructing episodic memory with construction. Trends in Cognitive Sciences, v. 11, p. 299-306, 2007.

HASSABIS, D.; SPRENG, R. N.; RUSU, A. A.; ROBBINS, C. A.; MAR, R. A.; SCHACTER, D. L. Imagine All the People: How the Brain Creates and Uses Personality Models to Predict Behavior. Cerebral Cortex, v. 24, issue 8, p. 1979-1987, 2014.

HASSABIS, D.; KUMARAN, D.; MAGUIRE, E. A. Using imagination to understand the neural basis of episodic memory. Journal of Neuroscience, v. 27, p. 14365-14374, 2007.

HASSABIS, D.; KUMARAN, D.; VANN, S. D.; MAGUIRE. E. A. Patients with hippocampal amnesia cannot imagine new experiences. Protocols Natl Acad Sci USA, v. 104, p. 1726-1731, 2007.

GALLAGHER, S: Neurons, neonates and narrative: From empathic resonance to empathic understanding In: FOOLEN, A.;U. LÜDTKE, U.; ZLATEV, J. and RACINE, T. (eds.), Moving Ourselves, Moving Others (167-96). Amsterdam: John Benjamins, 2012.

GALLAGHER, S. and HUTTO, D. Understanding Others Through Primary Interaction and Narrative Practice, In: ZLATEV, J.; RACINE, T.; SINHA, C. and ITKONEN, E. (eds.) The Shared Mind: Perspectives on Intersubjectivity. Amsterdam/Philadelphia: John Benjamins Publishing Company, 17-38, 2008.

HUME, D. A Treatise of Human Nature: Being an Attempt to Introduce the Experimental Method of Reasoning into Moral Subjects. Oxford: OUP, 2000.

LANDAUER, T. K.; BJORK, R. A. Optimum rehearsal patterns and name learning. In: GRUNENBER, M. M., MORRIS, P.E., SYKES, R. N. (Editors). Practical aspects of memory. New York: Academic Press, 1978. p. 625-632.

MAR, R. A. et al. Bookworms versus nerds: Exposure to fiction versus non-fiction, divergent associations with social ability, and the simulation of fictional social words. Journal of Research in Personality, v. 40, p. 694-712, 2006.

MOGRABI. G. J. C. Algumas relações entre Narrativas, Romance e a Psicologia Experimental da Cognição Literária e Habilidades Sociais. Eutomia, Recife, v. 15, n. 1, p. 123-144, jul. 2015.

. Sobre Naturalismos, Resistências Humanistas e a possibilidade de diálogo. Eutomia, Recife, v. 14, n. 1, p. 419-445, dez. 2014.

NAKAO, T.; OHIRA, H.; NORTHOFF, G. Distinction between externally vs. internally guided decision-making: operational differences, meta-analytical comparisons and their theoretical implications. Frontiers in Neuroscience, 2012.

QIN, P.; NORTHOFF, G. How is our self related to midline regions and the default-mode network? Neuroimage, v. 57, n. 3, p. 1221-1233, May 2011.

QUINLAN, P. T. Misuse of power: in defense of small-scale science. Nature Reviews Neuroscience, Correspondence, n. 14, 2013.

ROEDIGER III, H. L.; KARPICKE, J. D. The power of testing memory: basic research and implications for educational practice. Perspectives in Psychological Science, p. 181-210, 2006.

SCHACTER, D. L. Adaptive constructive processes and the future of memory. American Psychologist (APA), v. 67, p. 603-613, 2012. 
SCHACTER, D. L.; ADDIS, D. R.; BUCKNER, R. L. Episodic simulation of future events: concepts, data, and applications. Annals of the New York Academy of Sciences, v. 1124, p. 39-60, 2008.

. Remembering the past to imagine the future: the prospective brain. Nature Reviews Neuroscience, v. 8, p. 657-661, 2007.

SCHACTER, D. L.; ADDIS, D. R.; HASSABIS, D.; MARTIN, V. C.; SPRENG, R. N.; SZPUNAR, K. K. The future of memory: remembering, imagining, and the brain. Neuron, v. 76, p. 677-694, 2012.

Submetido em: 23/03/2016

Aceito em: 28/04/2016 